\title{
SUPERPARAMAGNETIC COBALT NANOCOMPOSITES SYNTHESIZED BY SOLVOTHERMAL SYNTHESIS IN A SINGLE STEP
}

\author{
CAROLINA A. CASTILLO ${ }^{a^{*}}$ AND PAULA A. SANTANA ${ }^{a}$ \\ ${ }^{a}$ Universidad Autónoma de Chile, Instituto de Ciencias Químicas Aplicadas, Facultad de Ingeniería, El Llano Subercaseaux 2801, \\ San Miguel, Santiago 8910060, Chile.
}

\begin{abstract}
In this work we are reporting the synthesis and characterization of superparamagnetic cobalt nanocomposites obtained from the direct reduction of cobalt(II) salts on matrices of graphene $(\mathrm{G})$ and carbon nanodisks/nanocones $(\mathrm{Ndc})$ in the presence of L-serine under solvothermal conditions. The synthesized nanocomposites were characterized by X-ray powder diffraction techniques identifying in all cases the peaks associated to the matrix (G or Ndc) and three peaks at $2 \theta$ values of 44,$2 ; 51,5 ; 75,8^{\circ}$, which correspond to the Miller indices (111), (200), (220), characteristic of a face-centered cubic Co ${ }^{0}$ phase. The SEM images of cobalt nanocomposites show that that using of a matrix changes the size and distribution of the metallic agglomerates, being possible to observe a more homogenous dispersion of the cobalt agglomerates on the Ndc matrix surface. Cobalt nanocomposites have a superparamagnetic behavior presenting $H c$ values of 14 and 60 Oe for NPs-Co $/ \mathrm{G}$ and $\mathrm{NPs}-\mathrm{Co}^{0} / \mathrm{Ndc}$ respectively. The superparamagnetic property of the cobalt nanoparticles and unique properties of the matrix would generate a magnetic material with interesting properties to be studied. More research is needed to give it a potential application.
\end{abstract}

Keywords: Nanoparticles, nanocomposites, solvothermal synthesis, superparamagnetic, cobalt.

\section{INTRODUCTION}

Over the past several years, the interest in nanoparticles has grown because of their unique electrical, magnetic, optical and catalytic properties ${ }^{1-5}$. Recently, magnetic nanoparticles have opened up novel vistas in the frontier field of nanotechnology due to their potential applications in high density magnetic recording, magnetic fluid, biomedical and microwave applications etc ${ }^{6-8}$. In particular, cobalt nanoparticles have been found to be pragmatic for a variety of applications such as catalysts, batteries, magnetic fluid and magnetic recording ${ }^{9}$ ${ }^{12}$. Co materials exhibit high resistance to oxidation, corrosion and wear. Many synthetic methods have been developed to prepare cobalt nanoparticles including solvothermal process ${ }^{13,14}$, thermal decomposition method $^{15}$, hydrothermal microemulsion process ${ }^{16}$ and high temperature solution phase method ${ }^{17}$.

Nanoparticles such as $\mathrm{Ni}, \mathrm{Fe}$ and $\mathrm{Co}$ have been supported on different matrices for example: silica, organic substances and polymers. Nanocomposites obtained from nanoparticles and polymeric matrix, are interesting due to the chemical nature and the structure of polymers, the presence of these changes the shape and size of the nickel nanoparticles ${ }^{18}$. Carbon is an excellent matrix because is more stable against oxidation, physical and chemical degradation. Carbon can provide good biocompatibility while protecting from agglomeration ${ }^{19,20}$. Also, with the recent emergence of graphene and because of the interesting and unique properties that it presents, many researchers have focused their studies on the synthesis of metal nanoparticles deposited on graphene matrix, in order to develop a magnetic material with interesting properties to be studied. The presence of defects on the graphene structure due to carbon vacancies influences the chemical and physical characteristics of graphene ${ }^{21}$ since it generates nonequivalent carbon atoms on the surface. Defect sites present higher reactivity for adsorption, which makes chemical functionalization an easy method to detect imperfections on graphene ${ }^{22}$. The defect sites in graphene can be used as starting points for the growth of nanoparticles. A previous experimental study suggests that the presence of defects on graphene substrates allows for controlled morphology of iron nanoparticles ${ }^{23}$ these graphene-supported nanocrystals may enhance the rate of electron transport while influencing the structural stability of the material, both effects potentially leading to enhanced surface reactivity ${ }^{24}$.

Carbon nanocones are the fifth allotropic form of carbon synthesized in $1997^{25}$ although they were first accidentally identified in 1994. The material found after the decomposition of hydro-carbons consisted of $20 \mathrm{wt} \%$ carbon nanocones and $70 \mathrm{wt} \%$ flat carbon disks ${ }^{26}$, being the rest amorphous carbon. Geometrically, they consist of curved graphite sheets with one or more pentagonal rings, defining a conical apex, which is extended by a rolled-up graphene sheet into a larger conical structure ${ }^{27}$. It is worth noting the unique electronic distribution provided by these pentagonal rings to the carbon nanocones, which results in an enhanced local density at the cone apex. This has been used as sorbent material in solidphase extraction (SPE) ${ }^{28}$.

In this paper, we presented the characterization of soft ferromagnetic cobalt nanocomposites obtained through solvothermal process.

\section{EXPERIMENTAL}

\subsection{Materials}

All the starting materials were commercially available reagents of analytical grade and were used without further purification.

\subsection{Synthesis of cobalt and cobalt nanocomposite}

The NPs-Co ${ }^{0}$ were obtained using solvothermal synthesis in the same synthetic conditions, as reported by Paredes-Garcia et $\mathrm{al}^{14}$. Due to the high stability obtained in nickel nanoparticles synthesis. The composites NPs-Co $\%$ G and NPs$\mathrm{Co}^{0} / \mathrm{Ndc}$ were obtained by incorporating a constant amount $(15 \mathrm{mg})$ of the graphene $(\mathrm{G})$ or carbon nanodisks/nanocones $(\mathrm{Ndc})$ matrix into a solution of cobalt (II) chloride in dimethylformamide in the presence of L-serine and heating the mixture at $170{ }^{\circ} \mathrm{C}$ under solvothermal conditions.

\subsection{Characterization}

All products were characterized by powder X-ray diffraction (PXRD) using a Bruker diffractometer, model D8 Advance with $\mathrm{Cu}$ Ka1 radiation and BraggBrentano geometry in the $5^{\circ} \leq 2 \theta \leq 80^{\circ}$ range. The data were obtained at $22^{\circ} \mathrm{C}$. A Carl Zeiss scanning electron microscope (SEM) coupled with an energy dispersive X-ray spectroscopy (EDXS), model EVO MA10, operated at $50.0 \mathrm{kV}$ and a JEOL transmission electron microscope (TEM) model JEM-1001L equipment were used to characterize morphology, composition, crystal structure and size distribution of the samples. A Vibrating Sample Magnetometer (VSM) PPMS Dyna Cool 9T was used to characterize the magnetic properties of asprepared nanoparticles.

\section{RESULTS AND DISCUSSION}

\section{Characterization of nanocomposites}

3.1 X-ray powder diffraction. The chemical nature and crystallinity of the synthesized products were identified by X-ray powder diffraction. Fig. 1 shows the diffraction patterns obtained for the Co nanoparticles, isolated matrices ( $\mathrm{G}$ and $\mathrm{Ndc}$ ) and nanocomposites. The nanoparticles display three peaks of different intensity at $2 \theta$ values 44,$2 ; 51,5 ; 75,8^{\circ}$ which correspond to the Miller Indices (111), (200), (220) respectively, and are characteristic of face-centered cubic $\mathrm{Co}^{0}$ (JCPDS file no. 15-0806, cubic system, spatial group: $\mathrm{Fm} 3 \mathrm{~m}$, $\mathrm{a}=3.5447 \AA)^{11}$. The measured XRD pattern is well matched with the previously reported XRD pattern ${ }^{29}$. No other phases are seen, indicating that the sample obtained is pure $f c c$ Co. Usually the cobalt nanoparticles are obtained as a mixture of phases ( $h c p-f c c)$ as was informed by M. Li et al. ${ }^{30}$ The G and Ndc matrices show a broad peak centered at $26.42^{\circ}$ corresponding to graphite (002) crystallographic plane ${ }^{31},{ }^{11}$.

These peaks together with the of $f c c \mathrm{Co}^{0}$ were observed in the diffraction patterns of the all nanocomposites. 


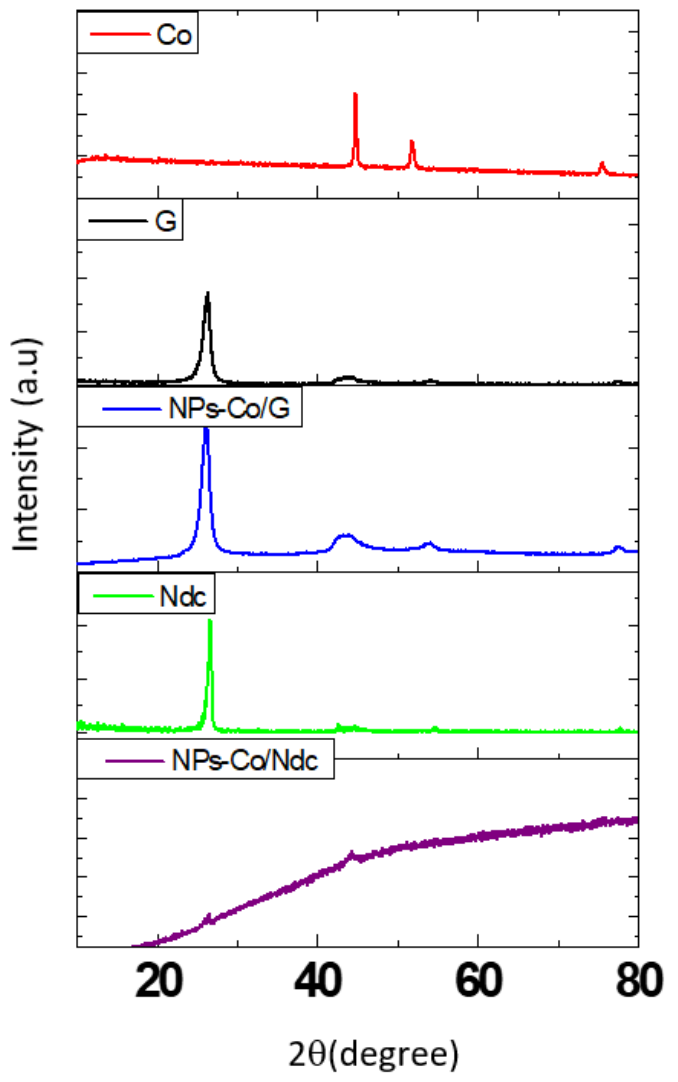

Figure 1. X-ray powder diffraction pattern of cobalt nanoparticles and nanocomposites (NPs- $\mathrm{Co}^{0}$, graphene matrix, NPs- $\mathrm{Co}^{0} / \mathrm{G}$ nanocomposite, $\mathrm{Ndc}$ matrix and $\mathrm{NPs}-\mathrm{Co}^{0} / \mathrm{Ndc}$ composite).

3.2 TEM and SEM microscopy analysis of NPs- $\mathrm{Co}^{0}$, NPs-Co $\%$ G and NPs$\mathrm{Co}^{0} / \mathrm{Ndc}$.

The size and surface morphology of the samples were analyzed through TEM and SEM images. The TEM image of the Co nanoparticles is presented in Fig. 2. The cobalt nanoparticles were spherical in shape with an average diameter of 20 and $50 \mathrm{~nm}$. Besides, the micrograph permits the observation of a thin organic coating. This coating was associated to the amino acid used as starting materials, which was also responsible for the stability of the $\mathrm{Co}^{0}$-NPs and avoided their oxidation reported by Santana $e t a b^{32}$. Fig. 3 shows the SEM images for NPs-Co ${ }^{0}$. We can see that they are forming homogeneous metallic agglomerates whit spherical shapes and sizes around $2 \mu \mathrm{m}$ of diameter, formed by small agglomerates, with size under $100 \mathrm{~nm}$, similar to those reported by D. Yang et $a l^{33}$.

Fig. 4 shows the distribution of the agglomerates cobalt on graphene matrix, in this case the spherical shape is the same to the agglomerates isolated. However is observed the sizes of this are different. We can see agglomerates of $100 \mathrm{~nm}$ until $1 \mu \mathrm{m}$. Fig. 5 shows the SEM data for nanocomposites of NPs-Co ${ }^{\circ} / \mathrm{Ndc}$. We can see that the distribution of the spherical metallic agglomerates on Ndc matrix is different to $\mathrm{G}$ matrix. In the Ndc matrix the dispersion of the agglomerates was in to nanocones and also on nanodisks due to morphological characteristics of the matrix. While the graphene matrix only permits a superficial distribution of metallic nanoparticles. On the matrix of Ndc it can be seen that the size of the metallic agglomerates is more uniform than in the graphene matrix, these are between 100 and $200 \mathrm{~nm}$.

Morphology of agglomerates metallic remains similar. Nevertheless, the size of these is smaller than to observed for the cobalt agglomerates in the absence of the matrix. The matrix promotes the spontaneous deagglomeration of the metallic aggregate. The morphology and sizes of nanoparticles obtained in our work are similar to the report by Yao et al. ${ }^{34}$. The author obtained spherical Co nanoparticles whit size around of $30 \mathrm{~nm}$ deposited on graphene, tested for heterogeneous oxidation of a dyeing pollutant, Orange II, with peroxymonosulfate (PMS) in aqueous solutions.

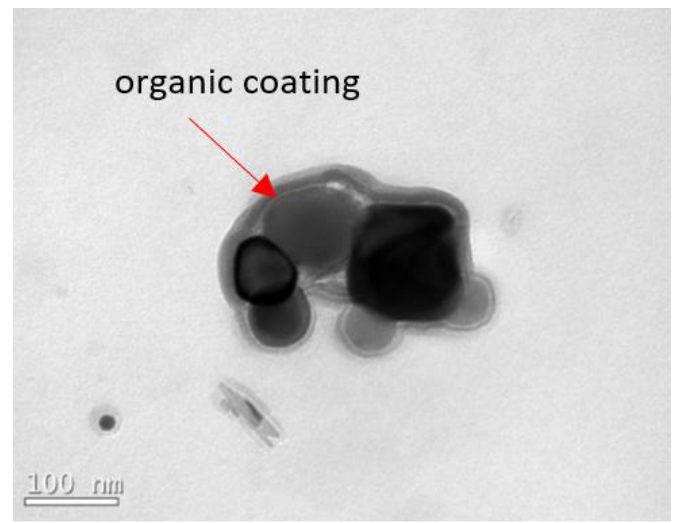

Figure 2. TEM image of NPs-Co ${ }^{0}$.

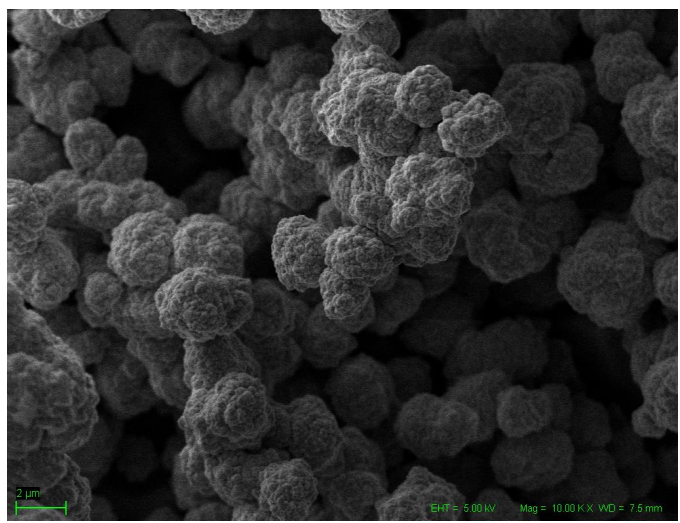

Figure 3. SEM image of NPs-Co ${ }^{0}$.

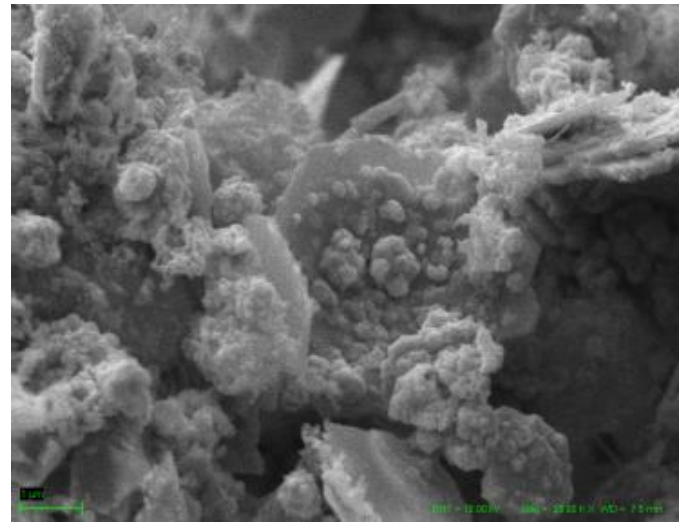

Figure 4. SEM image of NPs-Co $\%$ G.

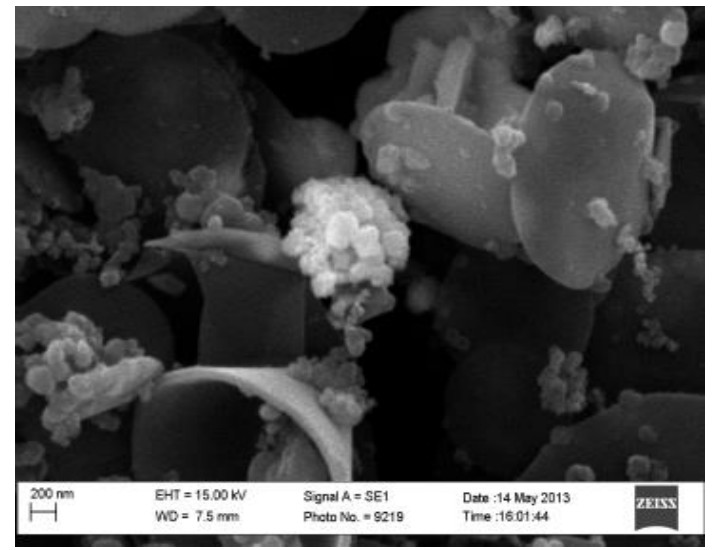

Figure 5. SEM image of NPs-Co ${ }^{0} / \mathrm{Ndc}$. 


\subsection{Magnetic characterization.}

The magnetic behavior for all products was investigated by vibrating sample magnetometer at $300 \mathrm{~K}$ under an external magnetic field sweeping from +20 to $-20 \mathrm{kOe}$. The magnetic hysteresis loop for products is shown in figure 6 . All the samples exhibited superparamagnetic behavior and showed higher values of coercivity $\left(H_{c}\right)$ than to those reported in literature for bulk cobalt $\left(H_{c}=10 \mathrm{Oe}\right)^{35}$. For NPs- $\mathrm{Co}^{0}$ the magnetic saturation $(M s)$, remanent magnetization $(\mathrm{Mr})$ and coercivity $(H c)$ of these are $149 \mathrm{emu} / \mathrm{g}, 3,88 \mathrm{emu} / \mathrm{g}$, and $56 \mathrm{Oe}$, respectively. For NPs-Co ${ }^{\circ} / \mathrm{Ndc}$ the $M s, M r$ and $H c$ of these are $94 \mathrm{emu} / \mathrm{g}, 2,70 \mathrm{emu} / \mathrm{g}$, and $60 \mathrm{Oe}$, respectively. Finally for NPs-Co $/ \mathrm{G}$ the parameters were $53 \mathrm{emu} / \mathrm{g}, 1 \mathrm{emu} / \mathrm{g}$ and $14 \mathrm{Oe} \mathrm{Ms}, \mathrm{Mr}$ and $\mathrm{Hc}$ respectively. The magnetic parameters measured for products and cobalt bulk are summarized in table 1. The presence of the matrix in the nanocomposites account for the lower magnetic saturation with respect to the isolated nanoparticles. The coercivity value for nanoparticles and nanocomposites of cobalt can be explained because the size of nanoparticles obtained by us is between 20 to $50 \mathrm{~nm}$ and are classified into single domain regime according to those graphic information observed by D. Kolhatkar et $\mathrm{al}^{37}$. This graphic show an overlap between two magnetic domain (single domain and multi domain) called "pseudo-single domain", and in this size the coercivity is not inversely proportional. Thus, our nanoparticles synthesized could be better classified into pseudo-single domain.

Table 1. Magnetic parameters of products and cobalt bulk

\begin{tabular}{|c|c|c|c|}
\hline Product & $\boldsymbol{M}_{\boldsymbol{s}}\left[\mathbf{e m u} \cdot \mathbf{g}^{-1}\right]$ & $\boldsymbol{M r}\left[\mathbf{e m u}^{-\mathbf{g}^{-1}}\right]$ & $\boldsymbol{H}_{\boldsymbol{c}}[\mathbf{O e}]$ \\
\hline Bulk Co & 163 & - & 10 \\
\hline NPs-Co & 149 & 3,88 & 56 \\
\hline NPs-Co ${ }^{0} / \mathrm{Ndc}$ & 94 & 2,70 & 60 \\
\hline NPs-Co $/ \mathrm{G}$ & 53 & 1 & 14 \\
\hline
\end{tabular}

On the other hand, in the nanocomposites a significant decrease in the value of $M s$ was observed. The reduction of $M s$, can be explained by the amount of metallic material present in the products. In this case, carbon nanodisks matrix contain more $\%$ of metallic cobalt than graphene matrix, see table 2. Possibly because the nanoparticles are deposited into and on of $\mathrm{Ndc}$ as is seen in the micrograph 5. Thus, this matrix can hold more metallic material.

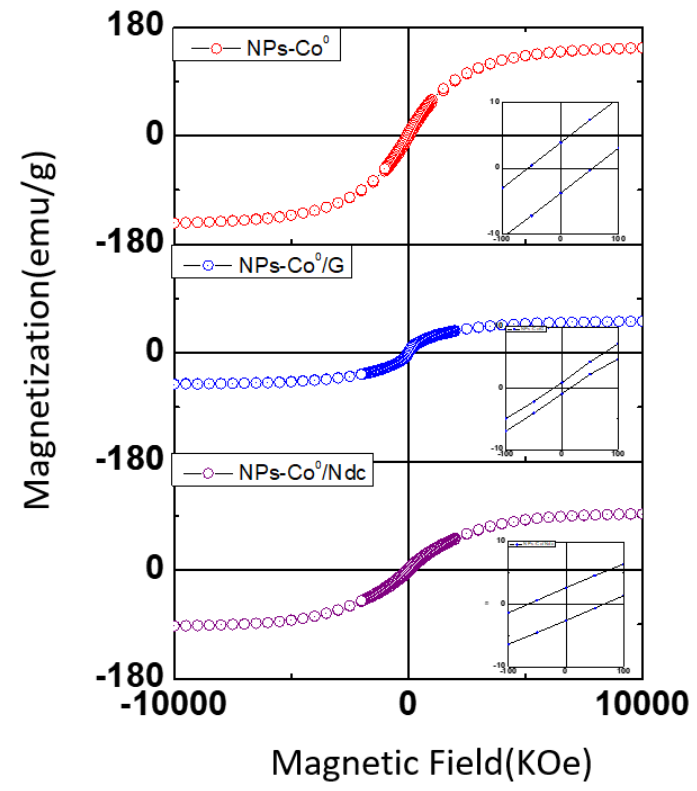

Figure 6. Hysteresis loops for NPs-Co; NPs-Co $\%$ G; NPS-Co $/ \mathrm{Ndc}$, measured at $300 \mathrm{~K}$.

Table 2. \% of metallic material in nanocomposite

\begin{tabular}{|l|c|}
\hline Nanocomposite & Co [\%] \\
\hline $\mathrm{NPs}-\mathrm{Co}^{0} / \mathrm{Ndc}$ & 64 \\
\hline $\mathrm{NPs}-\mathrm{Co}^{0} / \mathrm{G}$ & 38 \\
\hline
\end{tabular}

\section{CONCLUSIONS}

In conclusion, we report the synthesis and characterization of superparamagnetic cobalt nanocomposites: $\mathrm{NPs}-\mathrm{Co}^{\circ} / \mathrm{G}$ and $\mathrm{NPs}-\mathrm{Co}^{\circ} / \mathrm{Ndc}$ obtained by solvothermal synthesis in a single step. These cobalt nanocomposites were shown to have a superparamagnetic behavior at room temperature. It was observed that the insertion of the matrix did not change the crystalline structure of metallic phase $(f c c)$, either spherical morphology of the metallic agglomerates, however it reduced their size, being more significant in the Ndc matrix. Obtaining this interesting magnetic material opens the way for future studies in various areas and applications.

\section{CONFLICTS OF INTEREST}

The authors declare that they have no competing interest.

\section{ACKNOWLEDGEMENTS}

This work was funded by project DIUA 151-2019 from the Dirección de Investigación of Universidad Autónoma de Chile and FONDECYT project $\mathrm{N}^{\circ} 11170244$.

\section{REFERENCES}

1. H.X. Li, Z.F. Bian, J. Zhu, D.Q. Zhang, G.S. Li, Y.N. Huo, H. Li, Y.F. Lu, Mesoporous Titania Spheres with Tunable Chamber Structure and Enhanced Photocatalytic Activity, J. Am. Chem. Soc., 2007, 129, 8406-8407.

2. Q. Kuang, C.S. Lao, Z.L. Wang, Z.X. Xie, L.S. Zheng, High-Sensitivity Humidity Sensor Based on a Single $\mathrm{SnO}_{2}$ Nanowire, J. Am. Chem. Soc. 2007, 129, 6070-6071.

3. C.H. Lee, M. Kim, T. Kim, A. Kim, J. Paek, J.W. Lee, S.Y. Choi, K. Kim, J.B. Park, K. Lee, Ambient Pressure Syntheses of Size-Controlled Corundum-type $\mathrm{In}_{2} \mathrm{O}_{3}$ Nanocubes, J. Am. Chem. Soc., 2006, 128(29), 93269327.

4. R. Oxtermann, D. Li, Y.D. Yin, J.T. McCann, Y.N. Xia, $\mathrm{V}_{2} \mathrm{O}_{5}$ Nanorods on $\mathrm{TiO}_{2}$ Nanofibers: A New Class of Hierarchical Nanostructures Enabled by Electrospinning and Calcination, Nano Lett., 2006, 6, 1297-1302.

5. X.G. Han, Q. Kuang, M.S. Jin, Z.X. Xie, L.S. Zheng, J.D.H. Han, H.L. Luo, Z.J. Yang, Remanent and anisotropic switching field distribution of platelike Ba-ferrite and acicular particulate recording media, Magn. Magn. Mater. 1996, 161, 376-378.

6. M.H. Sousa, F.A. Tourinbo, New Electric Double-Layered Magnetic Fluids Based on Copper, Nickel, and Zinc Ferrite Nanostructures, J. Phys. Chem., 2001,B, 105, 1168-1175.

7. Kim, D., Nikles, D. E., Johnson, D. T. \& Brazel, C. S. Journal of Magnetism and Magnetic Materials Heat generation of aqueously dispersed CoFe $2 \mathrm{O} 4$ nanoparticles as heating agents for magnetically activated drug delivery and hyperthermia. 320, 2390-2396 (2008).

8. L. Chitu, Y. Chushkin, S. Luby, E. Majkova, A. Satka, J. Ivan, L. Smrčok, A. Buchal, M. Giersig, M. Hilgendorff, Structure and self-assembling of Co nanoparticles, Mater. Sci. Eng. C, 2007, 27, 23-28.

9. Y. Torres, M. Anglada, L. Llanes, Fatigue mechanics of WC-Co cemented carbides, Int. J. Refract. Met. Hard Mater., 2001, 19, 341-348.

10. M.P. Pileni, Magnetic Fluids: Fabrication, Magnetic Properties, and Organization of Nanocrystals, Adv. Funct. Mater., 2011, 11 323-336.

11. J.C. Yue, X.Y. Zhao, D.G. Xia, Electrochemical lithium storage of C/Co composite as an anode material for lithium ion batteries, Electrochem. Commun., 2012, 18 44-47.

12. C. Beatrice, V. Basso, M. Lo Bue, P. Tiberto, G. Bertotti, Experimental study of the magnetization processes in nanostructured soft magnetic materials, $\mathrm{J}$. Magn. Magn. Mater., 2003, 254, 158-160.

13. L.P. Zhu, W.D. Zhang, H.M. Xiao, Y. Yang, S.Y. Fu, Facile Synthesis of Metallic Co Hierarchical Nanostructured Microspheres by a Simple Solvothermal Process, J. Phys. Chem., 2008, C, 112, 10073-10078.

14. V. Paredes-Garcia, C. Cruz, J. Denardín, D. Venegas-Yazigi, C. Castillo, E. Spodine and Z. Luo, Effect of the Different Synthetic Parameters on the Morphology and Magnetic Properties of Nickel Nanoparticles, New J. Chem., 2014, 38, 837-844.

15. N. Matoussevitch, A. Gorschinski, W. Habicht, J. Bolle, E. Dinjus, H. Bonnemann, Surface modification of metallic Co nanoparticles, J. Magn. Magn. Mater., 2007, 311, 92-96.

16. W. Liu, W. Zhong, X. Wu, N. Tang, Y. Du, Hydrothermal microemulsion synthesis of cobalt nanorods and self-assembly into square-shaped nanostructures, J. Cryst. Growth., 2005, 284, 446-452.

17. Y. Su, X. Ouyang, J. Tang, Spectra study and size control of cobalt nanoparticles 
passivated with oleic acid and triphenylphosphine, Appl. Surf. Sci., 2010, 256, 2353-2356.

18. C. Castillo, K. Seguin, P. Aguirre, D. Venegas-Yazigi, A. D. C. Viegas, E. Spodine, V. Paredes-Garcia, Nickel Nanocomposites. Magnetic and Catalytic Properties, RSC Adv. 2015, 5, 63073-63079.

19. M. C, L. Bin, S. Huai-he, Z. Lin-jie, Preparation of carbon-encapsulated metal magnetic nanoparticles by an instant pyrolysis method, New Carbon Mater., 2010, 253 199-204.

20. Z. Abdullaeva, E. Omurzak, C. Iwamoto, H. Subban, S. Sulaimankulova, C. Liliang, T. Mashimo, Onion-like carbon-encapsulated $\mathrm{Co}, \mathrm{Ni}$, and $\mathrm{Fe}$ magnetic nanoparticles with low cytotoxicity synthesized by a pulsed plasma in a liquid, Carbon50(5), 2012, 1776-1785.

21. J. Carlsson, M. Scheffler, Structural, Electronic, and Chemical Properties of Nanoporous Carbon, Phys. Rev. Lett., 2006, 96, 46806-46810.

22. D. Boukhvalov, M. Katsnelson. Chemical Functionalization of Graphene with Defects, Nano Lett., 2008, 8(12), 4373-4379.

23. H. Wang, J. Robinson, G. Diankov, H. Dai, Nanocrystal Growth on Graphene with Various Degrees of Oxidation, J. Am. Chem. Soc., 2010, 132(10), 32703271.

24. P. Simon, Y. Gegotsi, Materials for electrochemical capacitors, Nat. Mater., 2008, 7, 320-329.

25. A. Krishnan, E. Dujardin, M.M.J. Treacy, J. Hugdahl, S. Lynum, T.W. Ebbesen, Nature, 1997, 388(6641), 451-454.

26. G. Helgesen, K.D. Knudsen, J.P. Pinheiro, A.T. Skjeltorp, E. Svaasand, H. Heiberg-Andersen, A. Elgsaeter, T. Garberg, S.N. Naess, S. Raaen, M.F. Tverdal, X. Yu, T.B. Meloe. Carbon Cones - a Structure with Unique Properties, Mater. Res. Soc. Symp. Proc. 2008, 1057.

27. M. Yudasaka, S. Iijima, V.H. Crespi, Single-Wall Carbon Nanohorns and Nanocones,Top. Appl. Phys., 2008, 111, 605-629.

28. J. M. Jimenez-Soto, S. Cardenas, M. Valcárcel, Evaluation of carbon nanocones/disks as sorbent material for solid-phase extraction, J Chromatogr. A., 2009, 1216, 5626-5633.
29. M. Alagiri, C. Muthamizhchelvan, S. Hamid, Synthesis of superparamagnetic cobalt nanoparticles through solvothermal process, J. Mater. Sci. Mater. Electron., 2013, 24(11), 4157-4160.

30. M.Li, K. Xie, Y. Wu, Q. Yang and L. Liao, Synthesis of cobalt nanowires by template-free method, Mater. Lett., 2013. 111, 185-187.

31. X. Du, H. Liu, C. Zhou, S. Moody, Y. Mai, On the flame synthesis of carbon nanotubes grafted onto carbon fibers and the bonding force between them, Carbon 50, 2012, 50, 2347-2374.

32. P. Santana, C. Castillo, S. Michea, D. Venegas-Yazigi, V. Paredes-Garcia $\mathrm{Co}^{0}$ superparamagnetic nanoparticles stabilized by an organic layer coating with antimicrobial activity, RSC Adv., 2020, 10(57), 34712-34718.

33. D. Yan, H. Zhao, Y. Liu, X. Wu, J. Pei, Shape-controlled synthesis of Cobalt particles by a surfactant-free solvothermal method and their catalytic application on the thermal decomposition of ammonium perchlorate Dong, Cryst Eng Comm, 2015, 17(47), 9062-9069.

34. Y. Yao, C.Xu, J. Qin, F. Wei, M. Rao and S. Wang, Synthesis of Magnetic Cobalt Nanoparticles Anchored on Graphene Nanosheets and Catalytic Decomposition of Orange II, Ind. Eng Chem Res, (2013), 52, 17341-17350.

35. G. Zhu, X. Wei, C. Xia, C and Y. Ye, Solution route to single crystalline dendritic cobalt nanostructures coated with carbon shells, Carbon 45, (2007), 45, 1160-1166.

36. A. Farghaly, Z. Huba and E. Carpenter, Magnetic field assisted polyol synthesis of cobalt carbide and cobalt microwires, J Nanoprta Res, (2012), 14, 1159-1163.

37. A. Kolhatkar, A. Jamison, D. Litvinov, R. Willson, T. Lee, Tuning the Magnetic Properties of Nanoparticles, Int J Mol Sci, (2013), 14, 15877 16009.

38. E. Vargas, P. Toro, J. Palma, J. Escrig, C. Chanéac, T. Coradin, J. Denardin, Facile synthesis and magnetic characterizations of single-crystalline hexagonal cobalt nanoplates, Mater Lett 94, (2013), 121-123. 